03,13

\title{
Влияние переходных металлов на диэлектрические свойства алмазоподобных кремний-углеродных пленок
}

\author{
(C) А.И. Попов ${ }^{1,2}$, А.Д. Баринов ${ }^{1,2}$, В.М. Емец ${ }^{1}$, Р.А. Кастро Арта ${ }^{3}$, А.В. Колобов ${ }^{3}$, \\ А.А. Кононов ${ }^{3}$, А.В. Овчаров ${ }^{4}$, Т.С. Чуканова ${ }^{1}$ \\ ${ }^{1}$ Национальный исследовательский университет „МЭИ“, \\ Москва, Россия \\ ${ }^{2}$ Институт нанотехнологий микроэлектроники РАН, \\ Москва, Россия \\ ${ }^{3}$ Российский государственный педагогический университет им. А.И. Герцена, \\ Санкт-Петербург, Россия \\ ${ }^{4}$ Национальный исследовательский центр „Курчатовский институт“, \\ Москва, Россия \\ E-mail: popovai2009@gmail.com \\ Поступила в Редакцию 28 мая 2021 г. \\ В окончательной редакции 28 мая 2021 г. \\ Принята к публикации 10 июня 2021 г.
}

\begin{abstract}
Проведены исследования влияния переходных металлов на фазовый состав, электрические и диэлектрические свойства алмазоподобных кремний-углеродных пленок, изготовленных плазмохимическим разложением полифенилметилсилоксана. Получены частотные, температурные и концентрационные зависимости указанных свойств. Показано, что с увеличением концентрации металла электропроводность непрерывно возрастает, а концентрационные зависимости диэлектрической проницаемости и тангенса угла диэлектрических потерь имеют минимум при концентрациях металла 0.5-2 at.\%. Анализируются возможные причины этого явления.
\end{abstract}

Ключевые слова: кремний-углеродные пленки, переходные металлы, структура, электропроводимость, диэлектрическая проницаемость, диэлектрические потери, концентрационные зависимости, поляризация.

DOI: $10.21883 /$ FTT.2021.11.51586.132

\section{1. Введение}

Аморфные алмазоподобные кремний-углеродные пленки являются относительно новым и интенсивно исследуемым видом покрытий, свободным от большинства недостатков алмазоподобных пленок аморфного углерода [1]. В [2] было показано, что высокая стабильность структурной сетки этих материалов позволяет в широких пределах управлять их свойствами методами структурной и химической модификаций. Это дает возможность получения покрытий с необходимыми механическими, трибологическими свойствами $[3,4]$ и электропроводностью $[5,6]$. Вместе с тем, исследований диэлектрических свойств указанных материалов значительно меньше. В [7] проведено исследование влияния типа кремнийорганического прекурсора, из которого плазмохимическим разложением изготовлялись пленки, на их диэлектрические свойства. Влияние же на эту группу свойств введения в материал примесей практически не исследовалось. В настоящей работе представлены результаты исследования влияния химической модификации алмазоподобных кремний-углеродных пленок переходными металлами на их диэлектрические свойства.

\section{2. Объекты и методы исследования}

Объектами исследования являлись металлосодержащие кремний-углеродные пленки, изготовленные плазмохимическим разложением полифенилметилсилоксана $\left(\mathrm{CH}_{3}\right)_{3} \mathrm{Si}\left[\mathrm{CH}_{3} \mathrm{C}_{6} \mathrm{H}_{5} \mathrm{SiO}\right]_{n} \mathrm{OSi}\left(\mathrm{CH}_{3}\right)_{3}$ (PPMS) с одновременным магнетронным распылением металла (титан, гафний) на установке, описанной в [2]. Конструкция установки позволяет получать в едином технологическом цикле набор образцов с различным содержанием металла в диапазоне от 0.2 до 10 at.\%, либо набор образцов с различным содержанием металла в диапазоне от 6 до 25-30 at.\%. Средняя концентрация металла в образцах, полученных в едином технологическом цикле, определяется положением подложек относительно плазмотрона и магнетрона. Пленки изготавливались на подложках из монокристаллического кремния для электрономикроскопических исследований и на металлических подложках (алюминий, нержавеющая сталь) для электрофизических измерений. В последнем случае на верхней поверхности пленки методом термического осаждения формировался электрод из алюминия диаметром 5-8 mm. Толщина пленок составляла от 1 до $3 \mu \mathrm{m}$. Температура подложкодержателя при синтезе пленок составляла $120-130^{\circ} \mathrm{C}$. 
Исследования структуры, фазового и элементного состава пленок проводилось методами электронной микроскопии высокого разрешения и дифракции на просвечивающем электронном микроскопе STEM/TEM Titan 80-300 (FEI, CША) и методом рентгеноспектрального микроанализа на растровом электронном микроскопе Vega II SBU (Tescan, Чехия) с энергодисперсионным детектором Inca x-Act (Oxford Instruments, Великобритания). Исследования электрофизических и диэлектрических свойств при различных температурах, проводились на установке для комплексного измерения диэлектрических свойств материалов Novocontrol Alpha-A (Германия) и на автоматизированной системе электрофизических измерений ASEC-03E (Россия). Исследования проводились при напряжениях от 1 до $5 \mathrm{~V}$, соответствующих омической области вольтамперных характеристик.

\section{3. Исследования структуры и фазового состава пленок}

Известно, что введение в кремний-углеродную пленку металлов при их содержании более 7-12 at.\% (в зависимости от вида металла) приводит к образованию двухфазной системы: аморфная кремний-углеродная матрица с внедренными в нее нанокристаллами размерами единицы $\mathrm{nm}$ [8]. При этом, последние представляют собой либо металл (при введении платины [9] или серебра [10]), либо карбид металла МеС (при введении переходных металлов [11]). Однако, проведенные в настоящей работе исследования фазового состава металлосодержащих пленок с невысоким содержанием металла показали, что в титансодержащих пленках при концентрациях металла от 0.5 до 4.0 at.\% и в гафнийсодержащих пленках с концентрацией металла от 0.5 до 2.5 at.\% нанокристаллическая фаза не наблюдается на электрономикроскопических изображениях высокого разрешения и не регистрируется при дифракционных исследованиях.

В качестве примера на рис. $1, a$ и $b$ приведены электроно-микроскопические изображения поперечного среза пленок и дифракционные картины от образцов c 2 at.\% титана и гафния. Для сравнения на рис. 1, и $d$ представлены аналогичные результаты для титани гафний-содержащих пленок с содержанием металла 20 at.\%.

Как видно из рисунков, на изображениях с высоким разрешением в случае пленок с низким содержанием титана (рис. 1, $a$ ) и гафния (рис. $1, b$ ) отсутствуют признаки периодичности в расположении атомов, а дифракционная картина представляет собой диффузное гало, типичное для аморфной фазы. В противоположность этому в случае пленок с высоким содержанием титана (рис. $1, c)$ и гафния (рис. $1, d$ ) на изображениях видны нанокристаллы с упорядоченным расположением атомов (отмечены белыми контурами), а электроно- грамма от этих областей имеет выраженные рефлексы (рис. 1, $d$ ).

Следует отметить, что отсутствие признаков кристаллической фазы в полученных экспериментальных данных не является доказательством отсутствия карбида металла в исследуемых образцах. Ранее [6] было установлено, что размеры нанокристаллов карбида металла зависят от вида введенного металла. Так при близких концентрациях металла (от 15 до 19 at.\%) средние диаметры нанокристаллов карбидов составляли: в случае МоС порядка $2.5 \mathrm{~nm}$, в случае НfC порядка $1.5 \mathrm{~nm}$, в случае ТаС от 4 до $8 \mathrm{~nm}$, в случае ТiC менее $2 \mathrm{~nm}$. Учитывая, что при высоких концентрациях металла размеры нанокристаллов карбидов гафния и титана в пленках составляют не более $2 \mathrm{~nm}$, разумно предположить, что при малых концентрациях этих металлов даже в случае формирования карбидных областей в пленке (т.е. областей с химическими связями металл-углерод), эти области не фиксируются на электрономикроскопических изображениях высокого разрешения как кристаллы и лежат ниже порога чувствительности дифракционных методов (т.е. образцы являются „электроно-аморфными“). Вместе с тем, отсутствие кристаллов проводящей фазы нанометровых размеров необходимо учитывать при интерпретации концентрационных зависимостей физических свойств рассматриваемых материалов.

\section{4. Исследования электрофизических свойств}

Зависимости электропроводности титансодержащих кремний-углеродных пленок от концентрации металла при разных температурах представлены на рис. 2. Там же приведена зависимость для гафнийсодержащих пленок при комнатной температуре.

Как и в случаях других металлов [6], введение титана и гафния в кремний-углеродную пленку вызывает рост электропроводности. Увеличение электропроводности пленок с ростом концентрации переходного металла, как правило, объясняют увеличением объема проводящих включений в пленке вследствие образования нанокристаллов карбида металла и соответствующим уменьшением эффективной толщины высокоомной кремнийуглеродной матрицы. Однако, как было показано выше, при концентрациях исследуемых металлов до 4 at.\% нанокристаллы в пленках вообще не наблюдаются. С другой стороны, в диапазоне концентраций металла от 0 до 4 at.\% электропроводность пленок возрастает на дватри порядка величины (см. рис. 2).

При анализе причин изменения свойств кремнийуглеродных пленок при введении в них переходных металлов необходимо принять во внимание, что атомы металла в пленке для образования связей металл-углерод заимствуют углерод из кремний-углеродной матрицы. Это приводит к изменению структуры и свойств последней. Указанные изменения могут заключаться в следующем. Во-первых, как отмечалось в [2], изъятие 
a

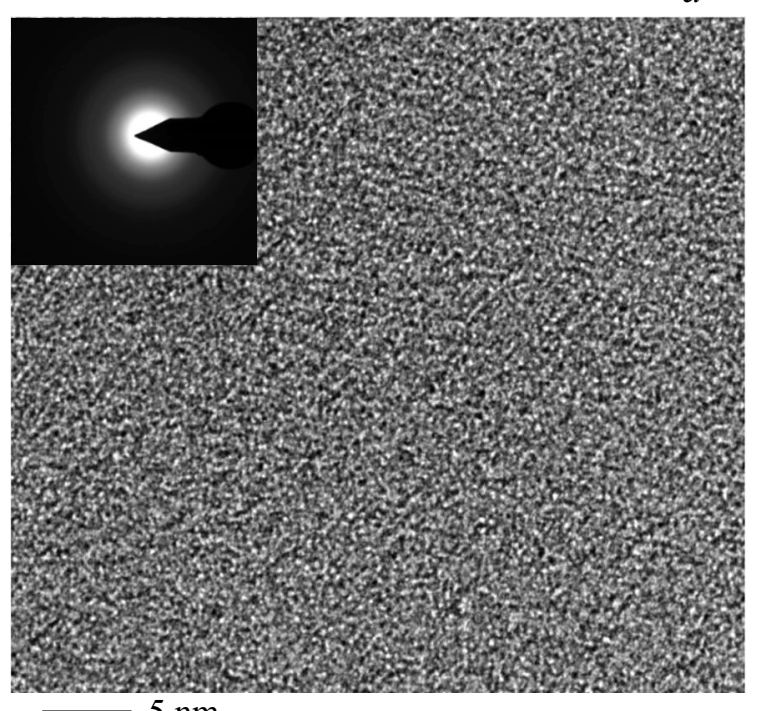

$c$

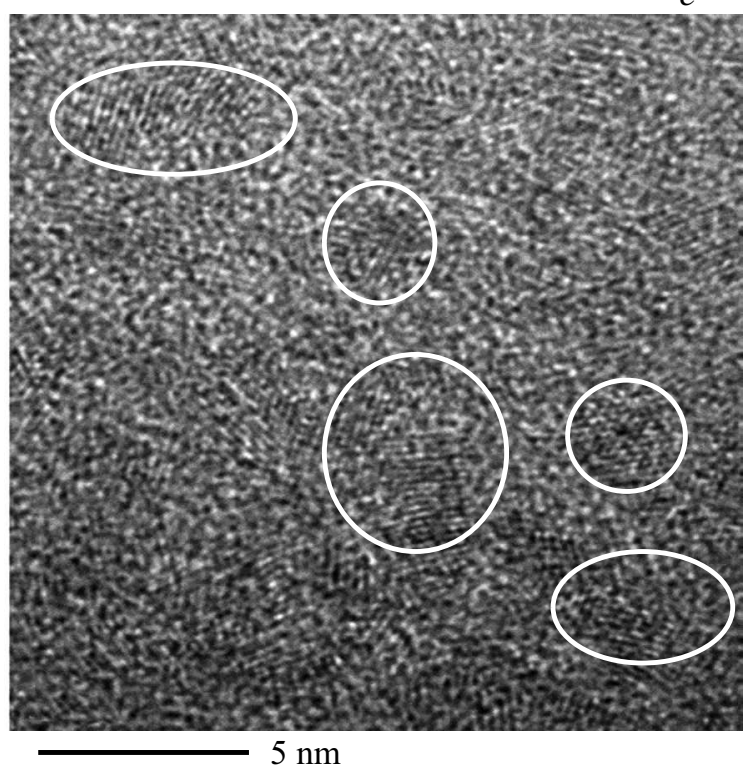

$b$

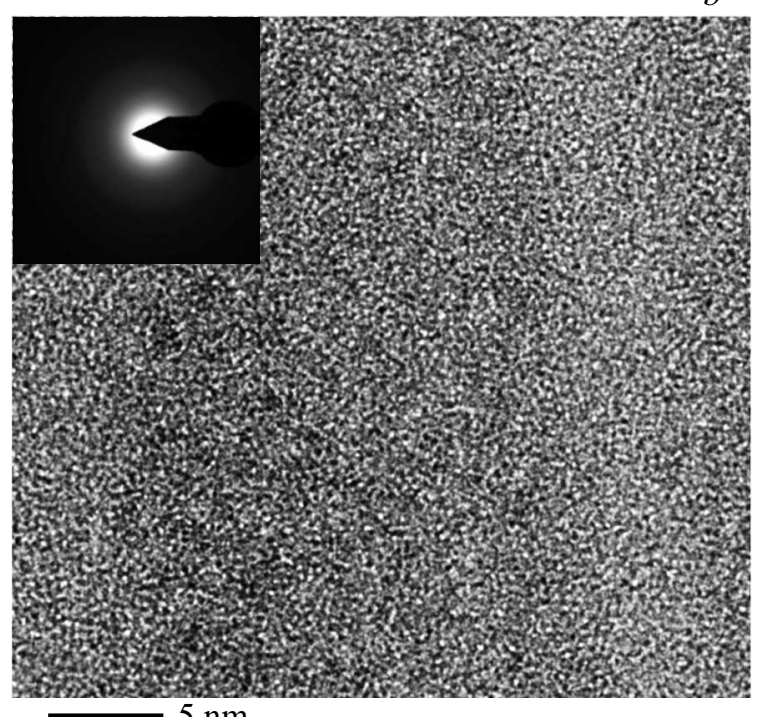

$d$

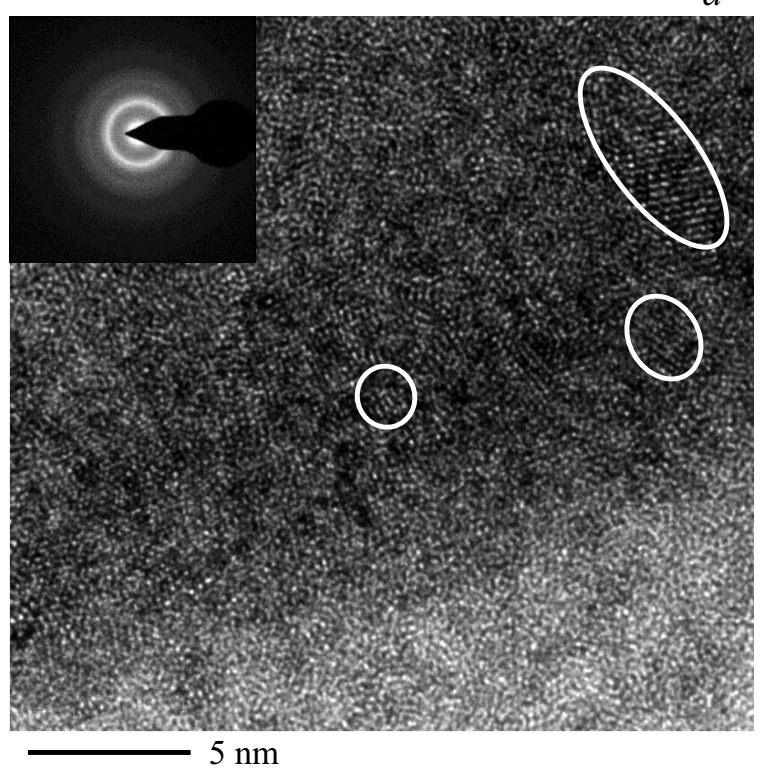

Рис. 1. ПЭМВР-изображения и дифракционные картины кремний-углеродных пленок с титаном $(a, c)$ и гафнием $(b, d)$ при содержании металла 2 at.\% $(a, b)$ и 20 at.\% $(c, d)$.

атомов углерода из структурной сетки ведет к росту концентрации оборванных связей и к увеличению плотности локализованных состояний в хвостах разрешенных зон. В свою очередь, это приводит к увеличению прыжковой проводимости в кремний-углеродной диэлектрической матрице. Во-вторых, как показали исследования спектров комбинационного рассеяния, введение в пленки аморфного углерода $[12,13]$ и в кремний-углеродные пленки $[14,15]$ некоторых переходных металлов (включая титан) приводит не только к образованию связей металл-углерод, но и к росту количества атомов углерода с $s p^{2}$-гибридизацией электронных орбиталей в исходной кремний-углеродной структурной сетке, при соответствующем уменьшении концентрации атомов с $s p^{3}$-гибридизацией. В свою очередь, возрастание доли атомов углерода с $s p^{2}$-гибридизацией также должно приводить к увеличению электропроводности кремнийуглеродных пленок.

Указанные причины с одной стороны могут объяснить существенное изменение электропроводности пленок при введении небольших концентраций металла и отсутствии кристаллической карбидной фазы, а с другой стороны иллюстрируют необходимость учета изменений атомной структуры кремний-углеродной матрицы при химическом взаимодействии с вводимыми в образец атомами переходных металлов.

Зависимости действительной части диэлектрической проницаемости от частоты электрического поля при разных температурах для образцов с различным содержанием титана и гафния представлены на рис. $3, a$ и $b$. 


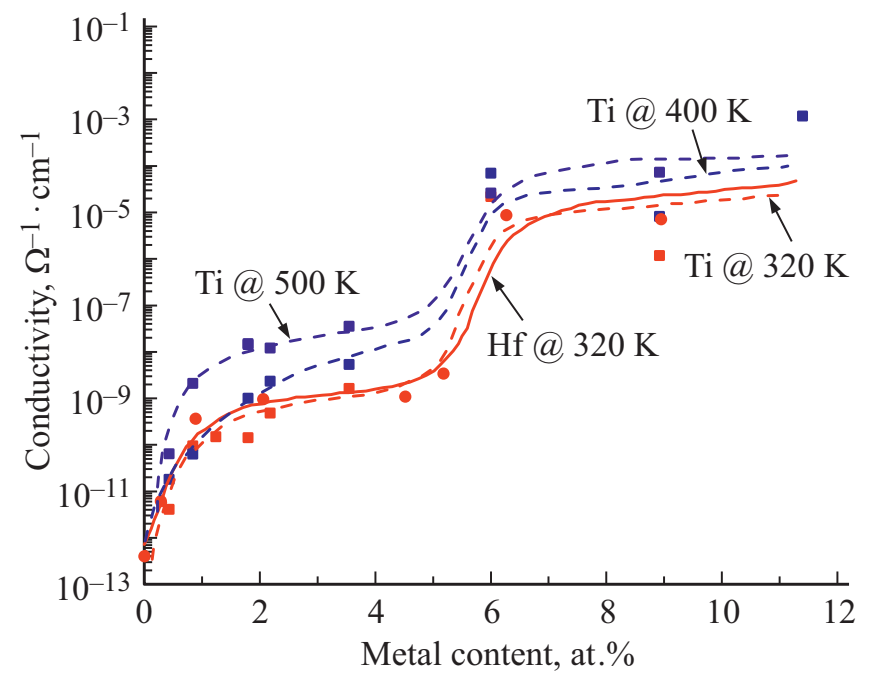

Рис. 2. Зависимость электропроводности кремний-углеродных пленок от концентрации в них титана при разных температуpax (штриховые линии) и гафния (сплошная линия).

Как видно из рисунков, действительная часть диэлектрической проницаемости для всех образцов имеет тенденцию к возрастанию с уменьшением частоты и с увеличением температуры. При этом величина указанных изменений зависит от концентрации металла в образце. В работе [7] было показано, что диэлектрическая проницаемость кремний-углеродных пленок на основе ПФМС без металла при высоких частотах $\left(10^{5}-10^{6} \mathrm{~Hz}\right)$ не зависит от частоты, а при уменьшении частоты менее $10^{5} \mathrm{~Hz}$ она начинает возрастать. В отличие от этого в образцах, содержащих металл, изменения диэлектрической проницаемости наблюдается и в высокочастотном диапазоне. Однако, если для образцов с содержанием титана до 1 at.\% эти изменения состав- ляют доли процента (что близко к пределу точности измерений), для образцов с содержанием от 1 до 2 at.\% изменения составляют единицы процентов, а у образца с содержанием металла 6 at.\% - более $40 \%$.

Возрастание значений диэлектрической проницаемости с увеличением температуры является характерной чертой полярных диэлектриков и обусловлено увеличением возможности ориентации диполей в электрическом поле. Причем плавный характер частотных зависимостей свидетельствуют о наличии в материале набора дипольных групп с различными временами релаксации поляризации. С уменьшением частоты приложенного электрического поля возрастает количество диполей, время релаксации которых $(\tau)$ обеспечивает возможность их участия в дипольно-ориентационной поляризации $(\tau \leq 1 / 2 f)$.

На рис. 4 показаны зависимости тангенса диэлектрических потерь от частоты электрического поля для кремний-углеродных пленок без металла (рис. 4,a) с титаном, с концентрацией 0.3 (рис. 4, $b$ ) и 1.8 at.\% (рис. 4,c) и с гафнием, с концентрацией 4.5 at.\%. Поскольку магнетронное распыление металла при изготовлении металлосодержащих пленок требует введение в рабочую камеру аргона, наличие которого также влияет на свойства пленок [2], то при изготовлении пленки без металла в рабочую камеру вводился аргон (с парциальным давлением $4.5 \cdot 10^{-4}$ Torr).

На зависимостях для образца с содержанием титана 0.3 at.\% обнаруживаются два „плеча“: в области частот порядка долей $\mathrm{Hz}$ при температурах выше $140^{\circ} \mathrm{C}$ („плечо 1“) и в области частот $1-10^{3} \mathrm{~Hz}$ при температурах выше $100^{\circ} \mathrm{C}$ („плечо $\left.2^{“}\right)$. В случае образца с содержанием титана 1.8 at.\% при температурах $60^{\circ} \mathrm{C}$ и выше „плечо 2“ на зависимостях преобразуется в пик в области частот от 10 до $10^{3} \mathrm{~Hz}$, который с увеличением температуры сдвигается в область высоких частот. Как
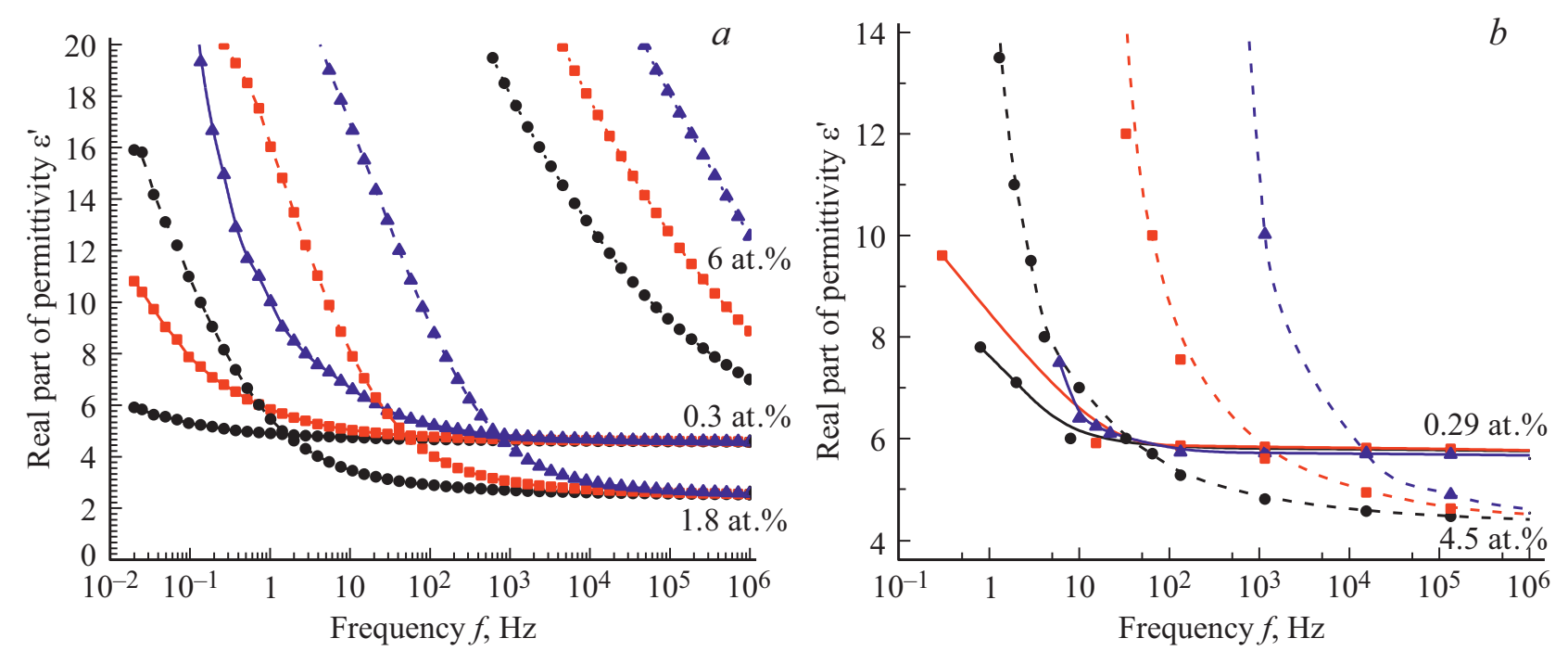

Рис. 3. Зависимости действительной части диэлектрической проницаемости от частоты для образцов с титаном $(a)$ и гафнием $(b)$ с различным содержанием металла при $20^{\circ} \mathrm{C}$ (кружки), $100^{\circ} \mathrm{C}$ (квадраты) и $200^{\circ} \mathrm{C}$ (треугольники). 

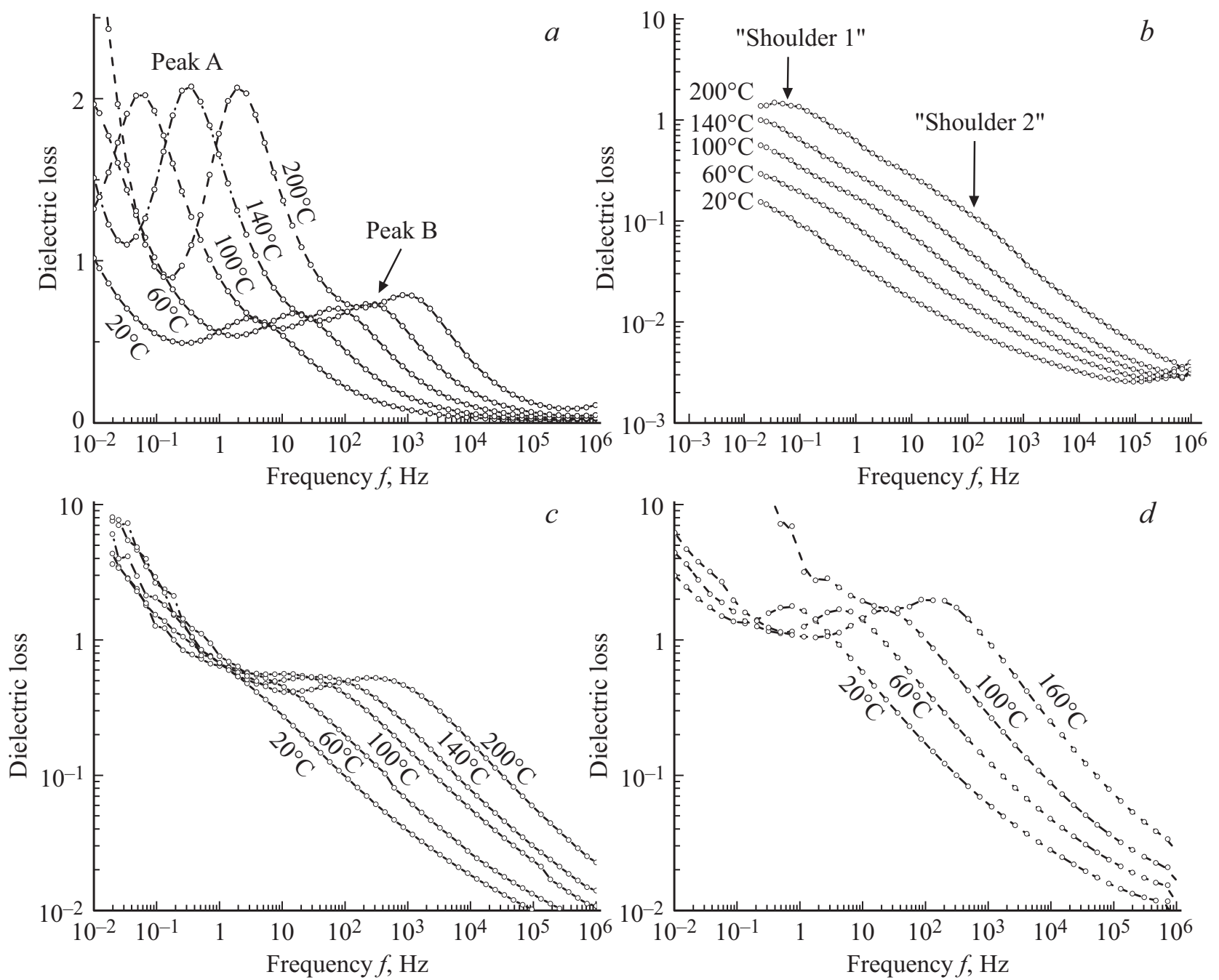

Рис. 4. Зависимость тангенса угла диэлектрических потерь от частоты для образцов без металла $(a)$, с титаном 0.3 at.\% $(b)$, 1.8 at.\% $(c)$ и гафнием 4.5 at.\% $(d)$ при разных температурах.

видно из рис. $4, d$, аналогичный вид частотных зависимостей тангенса угла диэлектрических потерь наблюдается и в образцах с гафнием. Такой вид зависимостей является подтверждением дипольного характера поляризации материала и объясняется наличием двух составляющих диэлектрических потерь в материале: релаксационные потери и потери на сквозную проводимость.

Потери на сквозную проводимость возрастают с увеличением температуры (рис. 2), а температурная зависимость релаксационных потерь имеет максимум, обусловленный двумя конкурирующими процессами: ориентацией диполей в электрическом поле и их дезориентацией вследствие тепловых колебаний. Анализ частотных зависимостей тангенса угла диэлектрических потерь с учетом потерь на сквозную проводимость и флуктуаций высоты потенциального барьера диполей проводился в рамках модели „релаксатора Фрёлиха“ [16] (рис. 5).

Согласно этой модели, у диполей в материале имеется два метастабильных состояния, разделенных потенциальным барьером $W_{\tau}$. Переход через этот потенци- альный барьер обеспечивает активационный характер времени релаксации:

$$
\tau=\tau_{0} \cdot \exp \left(\frac{W_{\tau}}{k T}\right),
$$

где $\tau$ - значение времени релаксации, sec; $\tau_{0}-$ предэксопненциальный множитель, sec; $k-$ постоянная Больцмана; $T$ - температура, $\mathrm{K}$.

Тогда релаксационные потери описываются выражением

$$
\operatorname{tg} \delta(\omega)=\operatorname{tg} \delta_{m} \frac{\operatorname{arctg}\left(\omega \beta / \omega_{m}\right)-\operatorname{arctg}\left(\omega / \omega_{m} \beta\right)}{\operatorname{arctg}(\beta)-\operatorname{arctg}(1 / \beta)},
$$

где $\omega_{m}=2 \pi f_{m}-$ значение частоты, соответствующее положению максимума релаксационных потерь $\operatorname{tg} \delta_{m}$, $1 / \mathrm{sec} ; \beta=\sqrt{\tau_{2} / \tau_{1}}-$ параметр, характеризующий уширение спектра (при $\beta=1$ выражение (2) преобразуется в формулу Дебая).

Полученные на основании этого анализа значения, входящие в выражение (2), сведены в таблицу. 


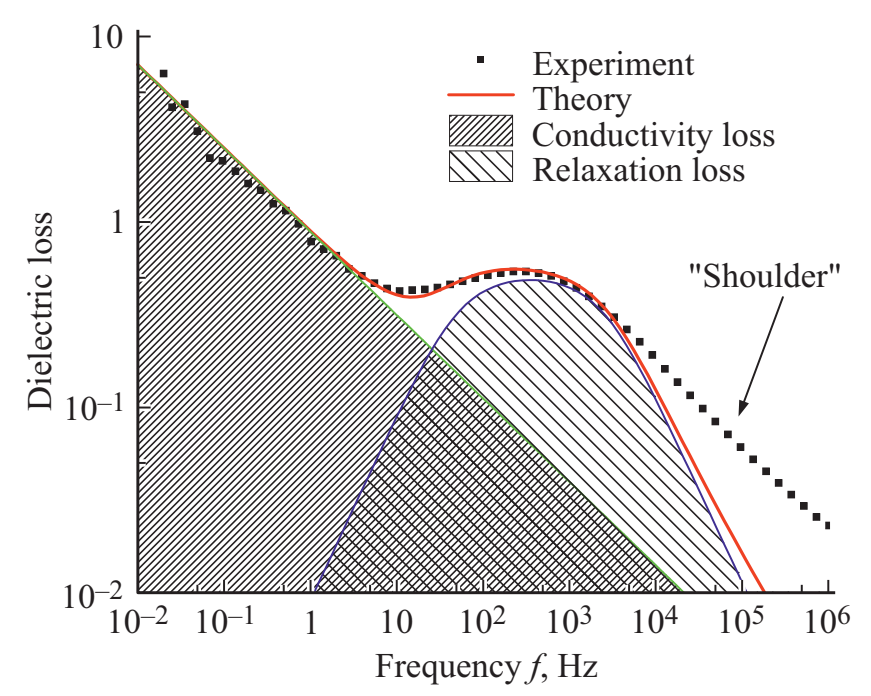

Рис. 5. Численный анализ частотной зависимости тангенса угла диэлектрических потерь для образца с содержанием титана 1.8 at.\% при температуре $200^{\circ} \mathrm{C}$.

Анализ температурных зависимостей времен релаксации в координатах Аррениуса $\ln \left(\tau_{1}\right)-1 / T$ и $\ln \left(\tau_{2}\right)-1 / T$ дал значения энергии активации релаксационных процессов в диапазоне от 0.42 до $0.46 \mathrm{eV}$. Кроме того, согласно [16], величина $\beta$ характеризует максимальный разброс высот потенциальных барьеров

$$
\Delta W_{\tau}=W_{\max }-W_{\min }=2 k T \cdot \ln (\beta) .
$$

Исходя из данных таблицы, максимальный разброс высот потенциального барьера составляет $\Delta W_{\tau}=$ $=(4.2-4.6) k T$.

Такой анализ позволил достаточно корректно воспроизвести указанные зависимости в окрестностях максимума и при более низких частотах. Вместе с тем, как видно из рис. 5 , на кривых справа от максимума наблюдается „плечо“, которое не описывается в рамках сделанных предположений. Причина возникновения этого „плеча“ заключается, вероятно, в наличии в материале ни одного, а нескольких типов релаксаторов с различными временами релаксации.

Аналогичный анализ температурного сдвига положения максимумов пиков на частотных зависимостях тан-

Параметры релаксационных потерь образца с 1.8 at.\% титана

\begin{tabular}{r|r|c|r|c|c}
\hline$T,{ }^{\circ} \mathrm{C}$ & $f_{m}, \mathrm{~Hz}$ & $\operatorname{tg} \delta_{m}$ & \multicolumn{1}{|c|}{$\beta$} & $\tau_{1}, \mathrm{sec}$ & $\tau_{2}, \mathrm{sec}$ \\
\hline 60 & 4.0 & 0.43 & 6 & $6.6 \cdot 10^{-3}$ & 0.24 \\
80 & 7.2 & 0.54 & 10 & $2.2 \cdot 10^{-3}$ & 0.22 \\
100 & 21.6 & 0.48 & 10 & $7.4 \cdot 10^{-4}$ & $7.4 \cdot 10^{-2}$ \\
120 & 27.0 & 0.53 & 8 & $7.4 \cdot 10^{-4}$ & $4.7 \cdot 10^{-2}$ \\
140 & 54.0 & 0.50 & 10 & $3.0 \cdot 10^{-4}$ & $3.0 \cdot 10^{-2}$ \\
160 & 135.6 & 0.44 & 10 & $1.2 \cdot 10^{-4}$ & $1.2 \cdot 10^{-2}$ \\
180 & 210.0 & 0.47 & 8 & $9.5 \cdot 10^{-5}$ & $6.1 \cdot 10^{-3}$ \\
200 & 350.0 & 0.48 & 9 & $5.1 \cdot 10^{-5}$ & $4.1 \cdot 10^{-3}$
\end{tabular}

генса угла диэлектрических потерь пленок без металла (рис. 4,a) и пленок с гафнием (рис. 4,d) показал, что энергия активации пика В в пленках без металла составляет $0.39 \mathrm{eV}$, а в пленках с гафнием $0.42 \mathrm{eV}$. Таким образом, энергии активации процессов релаксации во всех исследованных образцах близки друг к другу. Кроме того, положения пиков/плеч на рассматриваемых зависимостях для всех трех групп образцов также находятся в одном диапазоне частот. Данные факторы свидетельствуют о том, что как в пленках без металла, так и в пленках с невысоким содержанием металлов релаксаторы имеют одну и ту же природу и формируются в исходной кремний-углеродной матрице.

Из частотных зависимостей тангенса угла диэлектрических потерь (рис. 4) следует еще один интересный факт. У образца с содержанием титана 0.3 at.\% наблю-

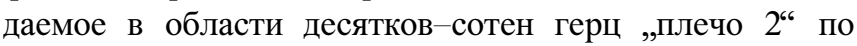
абсолютному значению практически на порядок ниже, чем пик в образце с 1.8 at.\% титана и пик В в образце без металла (несмотря на меньшие потери на сквозную проводимость в последнем). Это свидетельствует о меньшем содержании релаксаторов в образце с 0.3 at.\% титана по сравнению не только с образцом с бо́льшим содержанием титана, но с образцом, в котором металл отсутствует. Для анализа этого явления необходимо рассмотреть концентрационные зависимости свойств.

На рис. 6, а представлены зависимости диэлектрической проницаемости образцов при разной частоте измерений от концентрации введенных в них титана и гафния, а на рис. 6, $b$ концентрационные зависимости тангенса угла диэлектрических потерь для образцов с титаном. Характер концентрационных зависимостей $\operatorname{tg} \delta$ для образцов с гафнием имеет такой же характер.

Из рисунков видно, что как на зависимости диэлектрической проницаемости, так и на зависимости тангенса угла диэлектрических потерь от концентрации в пленке металла наблюдается минимум при содержании металла около 0.5-2 at.\%. При этом проводимость пленок с увеличением концентрации металла (рис. 2) непрерывно возрастает. Таким образом, при малых концентрациях введение металла вызывает рост проводимости и уменьшение диэлектрической проницаемости и тангенса угла диэлектрических потерь. Поскольку тангенс угла диэлектрических потерь зависит как от сквозной проводимости, так и от релаксационных потерь в образце, это свидетельствует, что введение металла при малых его концентрациях уменьшает релаксационные потери. Причем уменьшает их сильнее по сравнению с потерями на сквозную проводимость, которые растут при введении в пленку металла. Другими словами, введение металла в малых концентрациях (до 2 at.\%) приводит к уменьшению количества релаксаторов в материале. Для этого вводимый металл должен либо компенсировать дипольные моменты существующих релаксаторов, либо, что более вероятно, разрушать диполи, существующие в исходной матрице, за счет образования связей металлуглерод и, возможно, металл-кислород. 

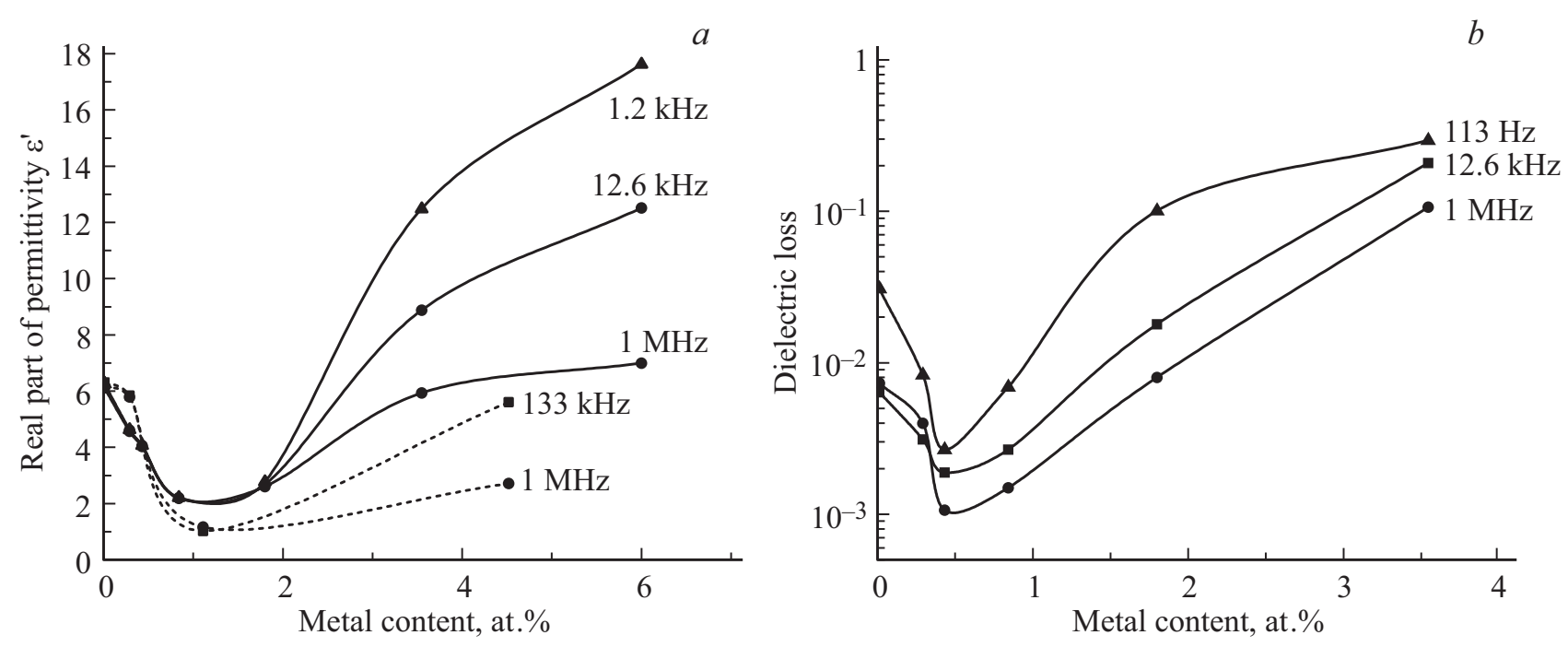

Рис. 6. Концентрационные зависимости диэлектрической проницаемости $(a)$ (сплошная линия - для пленок с титаном, штриховая - для пленок с гафнием) и тангенса угла диэлектрических потерь $(b)$ металлсодержащих кремний-углеродных пленок.

При увеличении концентрации металла более 2 at.\% возрастает объем фазы, содержащей соединения металла с элементами структурной сетки кремний-углеродной пленки, например, с углеродом. Эта фаза имеет повышенную электропроводность по сравнению с исходной матрицей. Благодаря этому возникает межфазная поляризация, приводящая к росту диэлектрической проницаемости и тангенса угла диэлектрических потерь. Такой вид поляризация для композитных материалов известен как поляризация Максвелла-Вагнера и наблюдался в работе [17] при исследовании пленок аморфного алмазоподобного углерода, модифицированных цинком. В работе показано, что при увеличении содержания цинка до 4 at.\% происходит монотонное возрастание диэлектрической проницаемости. Однако наличие минимума в области малых концентраций металла в работе обнаружено не было. Возможно, это связано с тем, что в пленках алмазоподобного углерода вводимый металл может соединиться только с атомами углерода, а в кремний-углеродных пленках могут реализовываться соединения металла с различными элементами структурной сетки [18].

\section{5. Заключение}

Проведенные исследования влияния переходных металлов на электрофизические свойства кремнийуглеродных пленок на основе PPMS показали различный характер концентрационных зависимостей исследованных свойств. Так, электропроводность пленок непрерывно возрастает с увеличением концентрации металла, а зависимости диэлектрической проницаемости и тангенса угла диэлектрических потерь имеют минимум в диапазоне концентраций металла 0.5-2.0 at.\% металла. Уменьшение значений диэлектрических свойств при вве- дении относительно небольших концентраций металла (несмотря на рост сквозной проводимости) свидетельствует о существенном снижении релаксационных потерь в материале. Причина этого явления может заключаться в разрушении существующих в исходной матрице диполей за счет образования соединений металла с элементами структурной сетки (углеродом и кремнием). При этом необходимо отметить, что высказанное предположение является гипотезой, для подтверждения которой необходимо проведение экспериментов по количественному определению наличия и концентрации химических связей атомов металла с элементами структурной сетки при разных концентрациях металла.

\section{Финансирование работы}

Работа выполнена при финансовой поддержке Российского фонда фундаментальных исследований (грант № 19-07-00021).

Часть экспериментальных работ была выполнена на оборудовании Ресурсного центра зондовой и электронной микроскопии (Курчатовский комплекс НБИКС природоподобных технологий, НИЦ „Курчатовский институт“).

\section{Конфликт интересов}

Авторы заявляют, что у них нет конфликта интересов.

\section{Список литературы}

[1] Š. Meškinis, A. Tamulevičienè. Mater. Sci. (Medžiagotyra) 17, 4, 358 (2011).

[2] А.И. Попов, А.Д. Баринов, В.М. Емец, Т.С. Чуканова, М.Л. Шупегин. ФТТ 62, 10, 1612 (2020). 
[3] F. Mangolini, B.A. Krick, T.D.B. Jacobs, S.R. Khanal, F. Streller, J.B. McClimon, J. Hilbert, S.V. Prasad, T.W. Scharf, J.A. Ohlhausen, J.R. Lukes, W.G. Sawyer, R.W. Carpick. Carbon. 130, 127 (2018).

https://doi.org/10.1016/j.carbon.2017.12.096

[4] E.V. Zavedeev, O.S. Zilova, M.L. Shupegin, A.D. Barinov, N.R. Arutyunyan, T. Roch, S.M. Pimenov. Appl. Phys. A 122, 961 (2016). DOI: 10.1007/s00339-016-0508-7

[5] М.А. Величко, Ю.П. Гладких. Науч. вед-ти Белгородского нац. исслед. ун-та. Сер. Математика. Физика 6, 227; 42, 115 (2016).

[6] А.Д. Баринов, А.И. Попов, М.Ю. Пресняков. Неорган. материалы 53, 7, 706 (2017).

[7] А.Д. Баринов, Т.Д. Гуринович, А.И. Попов, Т.С. Чуканова, М.А. Шапетина, М.Л. Шупегин. Неорган. материалы. 56, 8,844 (2020).

[8] A. Popov. Disordered Semiconductors: Physics and Application. 2nd ed. Pan Stanford Publish. (2018). 328 p.

[9] М.Д. Малинкович, Ю.Н. Пархоменко, Д.С. Поляков, М.Л. Шупегин. Материалы электронной техники 1, 3, 41 (2010).

[10] T. Tamulevičius, D. Tamulevičiené, A. Virganavičius, V. Vasiliauskas, Š. Kopustinskas, S. Meškinis. Nucl. Instrum. Meth. Phys. Res. B 341, 1 (2014).

[11] М.Ю. Пресняков, А.И. Попов, Д.С. Усольцева, М.Л. Шупегин, А.Л. Васильев. Рос. нанотехнологии 9, 7-8, 70 (2014).

[12] D.B.K. Sheeja, C.Q. Tay et al. J. Mater. Sci. 38, 421 (2003).

[13] C.M. Adelhelm, M. Balden, Rinke etal. J. Appl. Phys. 105, 033522 (2009)

[14] A. Bozhko, T. Takagi, T. Takeno. J. Phys. Condens. Matter 16, 46, 8447 (2004).

[15] S.M. Pimenov, E.V. Zavedeev, N.R. Arutyunyan, O.S. Zilova, A.D. Barinov, M.Yu. Presniakov, M.L. Shupegin. Surface \& Coatings Technology 402, 126300 (2020).

[16] Г. Фрёлих. Теория диэлектриков. Диэлектрическая проницаемость и диэлектрические потери. ИЛ, М. (1960). 251 с.

[17] A.K. Das, R. Hatada, W. Ensinger. J. Alloys Comp. 758, 194 (2018).

[18] А.И. Попов, В.П. Афанасьев, А.Д. Баринов Ю.Н. Бодиско, А.С. Грязев, И.Н. Мирошникова, М.Ю. Пресняков, М.Л. Шупегин. Поверхность. Рентгеновские, синхротронные и нейтронные исследования 9, 49 (2019).

Редактор К.В. Емщев 